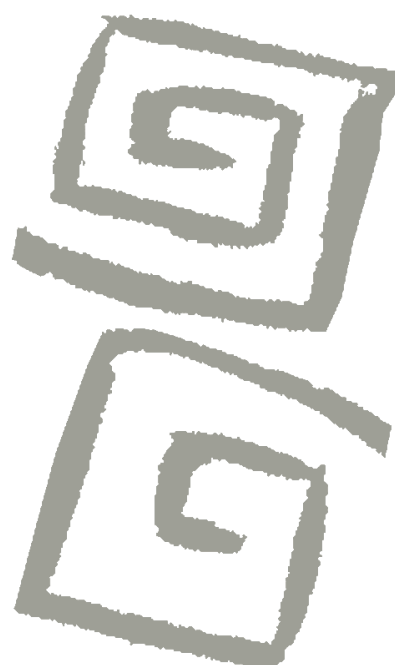

\title{
"Nos temen porque somos Otro": actitudes hacia las personas con discapacidad en la Rusia moderna
}

\author{
"They fear us because we are Other": attitudes \\ towards disabled people in today's Russia
}

Elena Nosenko-Stein ${ }^{1}$

'Socióloga, Doctora en Historia. Investigadora Senior, Instituto de Etnología y Antropología, Academia de Ciencias de Rusia. Moscú, Federación Rusa. $\bowtie$ (iD)
RESUMEN El número de personas con discapacidad en la Rusia postsoviética supera los 13 millones, pero hasta el momento se han realizado muy pocas investigaciones sobre los procesos que se desarrollan dentro de este gran sector de la sociedad. El objetivo de este artículo es abordar las diferentes nociones y estereotipos relacionados con la discapacidad. Desde el abordaje metodológico de la historia oral se realizaron entrevistas en profundidad a 11 hombres y 16 mujeres con discapacidad en tres regiones de Rusia, además de seis entrevistas a expertos en Moscú y Nizhny Novgorod. También fueron incorporados relatos sobre la experiencia de discapacidad publicados en Internet. El análisis de estas fuentes muestra que la percepción de las personas con discapacidad y de la discapacidad en general es ambivalente e impacta en la percepción de la discapacidad y la autoidentificación que tienen las propias personas discapacitadas que forman parte de la sociedad rusa.

PALABRAS CLAVES Personas con Discapacidad; Percepción Social; Investigación Cualitativa; Rusia.

ABSTRACT Although the number of disabled people in post-Soviet Russia exceeds 13 million, research regarding many processes occurring within this large segment of the society remains scant. The objective of this article was to examine the different notions and stereotypes dealing with impairments. Using the qualitative approach of oral history, in-depth interviews with 11 men and 16 women with disabilities were carried out in three regions of Russia, as were interviews with six experts in Moscow and Nizhny Novgorod. In addition, accounts of disability experience published in online journals were examined. The analysis of these sources shows that the perception of disabled people and disability in general is ambivalent and impacts the perception of disability and selfidentification of disabled people who are also a part of Russian society.

KEY WORDS People with Disabilities; Social Perception; Qualitative Research; Russia. 


\section{INTRODUCCIÓN}

El estudio de los problemas de las "personas discapacitadas" como fenómeno social se expandió ampliamente en la década de 1960, sobre todo a partir de las obras clásicas de Goffman y Allort ${ }^{(1,2)}$. En la misma época, crecieron los movimientos que apoyaban a las diferentes minorías, incluso a las personas con discapacidad. A lo largo de las últimas cuatro décadas, los estudios de discapacidad se convirtieron en un campo académico interdisciplinario que incorpora a las ciencias sociales, las humanidades, las artes y la medicina, entre otras.

En la ex Unión de Repúblicas Socialistas Soviéticas (URSS), los estudios sobre discapacidad fueron realizados dentro del marco del modelo médico, que considera a la discapacidad como fenómeno de intervención clínica, como enfermedad o defecto que debería ser manejado a través del cuidado médico. De esta manera se formó una importante escuela de estudios de defectos (actualmente pedagogía correctiva) para la enseñanza de niños/as con discapacidad. A modo de ejemplo, la enseñanza y rehabilitación de niños/as ciegos (tifología), la enseñanza de niños/as y adolescentes sordos/as (surdología) y la rehabilitación de niños/as sordociegos/as (tifosurdología) emergieron como tendencias especiales en los estudios de la discapacidad, y se han Ilevado a cabo numerosas investigaciones interesantes en estos campos. Sin embargo, los estudios en discapacidad aún son incipientes en la Rusia postsoviética, más allá de algunas publicaciones interesantes sobre políticas sociales, aspectos de discapacidad relacionados con el género y otros temas similares ${ }^{(3,4,5)}$.

Como campo interdisciplinario, los estudios en discapacidad incluyen enfoques y métodos que han sido aplicados en otras ciencias sociales y humanidades, tales como la antropología sociocultural, la sociología, la psicología, la historia, los estudios de foIklore, la etnografía y los estudios literarios. Sin embargo, en la Rusia contemporánea estas disciplinas nunca o casi nunca tocan la discapacidad como fenómeno cultural, o como un conjunto de problemas de personas con distintas deficiencias, discapacidades o defectos que involucran nociones tan variadas como: enfermedad/salud; cuerpo capacitado/discapacitado; empatía/agresión; estereotipos y etiquetas asociados con distintos tipos de discapacidades (ceguera, enfermedades mentales); y la representación y autorepresentación de personas con discapacidad en la cultura popular, la literatura, los medios masivos, las narrativas orales, etc.

\section{Algunas estadísticas y definiciones}

Según los datos de la Organización Mundial de la Salud (OMS), las personas con discapacidad constituyen una décima parte de la población mundial, es decir, unas 650 millones de personas ${ }^{(6)}$. A su vez, la OMS afirma que, en 2011, aproximadamente 1-1,5 mil millones de personas contaban con algún tipo de discapacidad a nivel mundial ${ }^{(7)}$. Estas estadísticas dependen del sistema de salud, los criterios de registro de distintas deficiencias y la situación política (guerras, conflictos, hambrunas, etc.) en cada región. Hay además diferentes maneras de definir discapacidad, deficiencia o defecto. Adicionalmente, el alto nivel de desarrollo que alcanza la medicina en los países occidentales también resulta en discapacidad, ya que personas (incluso bebés) que hace unas décadas hubiesen fallecido como resultado de enfermedad o trauma ahora sobreviven, y frecuentemente con discapacidad.

Según las estadísticas rusas oficiales, hay alrededor de 12,9 millones de personas discapacitadas registradas dentro de los grupos 1 y $2^{(8)}$. Desde el periodo soviético, los grupos de discapacidad en Rusia se definen según su posibilidad de trabajo y no según la enfermedad o defecto, por lo que hay tres categorías de discapacidad en general: grupo 1 (personas que no pueden trabajar o trabajan en esferas limitadas, como personas ciegas que pueden trabajar como masajistas o músicos); grupo 2 (personas que solo pueden trabajar en condiciones especiales, como en fábricas 
para personas discapacitadas, o que no pueden trabajar; quienes están en este grupo reciben pensiones más bajas que los que están en grupo 1); y grupo 3 (personas que pueden trabajar; en muchos casos este grupo se define como temporario, por ejemplo, después de sufrir un trauma, una persona discapacitada puede recuperar su salud a lo largo de uno o varios años y volverse "capacitada"). De esta manera, las estadísticas rusas no tienen en cuenta las personas con discapacidad del grupo 3, es decir, las discapacidades relativamente "menores". Adicionalmente, quienes no están registrados como discapacitados por las experticias médicas y sociales no figuran en los datos estadísticos; algunas personas no lo hacen porque no quieren perder un buen empleo, otros no quieren invertir el tiempo que lleva el trámite solo para percibir una pequeña pensión. Algunos expertos creen que hay 14 o hasta 15 millones de personas con discapacidad en Rusia, a pesar de la política social de aumento de las restricciones, que dificulta su tramitación.

No solo son vagas las estadísticas, sino que no existe una definición general de discapacidad que sea utilizada por organizaciones internacionales o en la investigación académica. Según la Convención sobre los Derechos de las Personas con Discapacidad de las Naciones Unidas, la discapacidad es la consecuencia de defectos fisiológicos o funcionales que resultan de la enfermedad, los accidentes o similar ${ }^{(9)}$. La OMS diferencia "deficiencias" (la falta de un aparato, disfunción o anormalidad fisiológico o mental), "minusvalía" (dificultades en actividades o funciones normales como resultado de una deficiencia) y "discapacidad" (limitaciones en las actividades humanas resultantes de defectos innatos o adquiridos) $)^{(10)}$. Como resultado de esta falta de uniformidad en la definición, varias organizaciones tanto a nivel nacional como a nivel internacional presentan estadísticas diferentes.

\section{Algunos abordajes y modelos}

Desde la antigüedad han existido diversas nociones, etiquetas, estereotipos e incluso miedos relacionados con las diferentes deficiencias y las personas discapacitadas en diferentes culturas. Estos incluyen nociones con respecto a la amenaza que representa la ceguera y hasta advertencias sobre su contagiosidad $^{(11)}$ y la percepción de personas con discapacidad mental como peligrosas y socialmente inaceptables ${ }^{(12)}$. En las Ilamadas "culturas primitivas" (pueblos que vivieron o aún viven en condiciones de economías apropiativas), algunos defectos fisiológicos y especialmente mentales se consideraban resultantes de algún rasgo negativo de la persona. A lo largo de los últimos 50 años, el problema de la percepción de la discapacidad y las nociones sobre personas discapacitadas en diferentes culturas y épocas ha sido explorado ampliamente ${ }^{(11,13,14,15,16,17)}$.

La terminología y las definiciones de discapacidad dependen del abordaje dado al fenómeno. En el siglo XIX y la primera mitad del siglo XX, el modelo médico de la discapacidad era el más difundido. Según este enfoque, la discapacidad es un problema médico (enfermedad o trastorno funcional, el resultado de trauma, etc.) que se debería manejar por medios médicos. Así, la discapacidad es siempre una tragedia, un trauma personal y una experiencia personal anormal. Es a partir de este modelo médico que se genera un interés en el traumatismo en varias culturas. Aún más, dentro del marco de este modelo, una persona discapacitada es un individuo digno de lástima y debe ser cuidado (por su familia, por la sociedad y, especialmente, por las organizaciones filantrópicas). Este y otros enfoques han sido descritos detalladamente en la bibliografía $^{(16,18,19)}$. De esta manera, se puede observar una oposición "discapacidad-salud" típica de este enfoque y la sociedad rusa en general $^{(19)}$.

Durante los últimos 50 años ha predominado un modelo social de discapacidad. En este marco, la discapacidad es un constructo social; las instituciones sociales y los contextos sociales generan dicho constructo y crean numerosas restricciones para personas con discapacidad ${ }^{(16)}$. Según este enfoque, las personas discapacitadas son la parte más 
discriminada de la sociedad, que es responsable de su discriminación. La socióloga rusa larskaia-Smirnova enfatiza que la discapacidad es el resultado de un acuerdo social y el significado de este constructo depende de las tradiciones, las diferencias sociales, el estatus y cuestiones similares ${ }^{(20)}$. En años recientes, este enfoque ha sido criticado en ocasiones por no tomar en cuenta el contexto cultural y hasta algunas realidades fisiológicas y psicológicas, como el dolor y la incomodidad física y emocional(18).

Hay además otros abordajes de la discapacidad, aunque no siempre se mencionan. Entre ellos se destacan el enfoque afirmativo (positivo) que emergió como resultado de las actividades creativas de las personas con discapacidad, concentrándose en el valor de su experiencia cultural y no en la tragedia y el trauma. Según este enfoque, la discapacidad es una experiencia única de gran importancia para una sociedad. Otros abordajes de la discapacidad surgen de un enfoque legislativo (de derechos humanos), un enfoque corporal u otros apuntados a los derechos humanos de personas con discapacidad y la representación de sus cuerpos ${ }^{(15,16,17,21)}$. Sin embargo, el enfoque sociocultural parece el más complejo y prometedor, combinando las ventajas de otros enfoques. Según este abordaje, una sociedad es un sistema social y cultural que incluye a las personas con discapacidad; las experiencias y posibilidades de estas personas están determinadas por cada sociedad en particular ${ }^{(16,19)}$.

Algunos estereotipos de personas con diferentes deficiencias son ampliamente difundidos en las sociedades modernas, incluyendo Rusia. Entre ellos se encuentran las etiquetas de "inútiles", "defectuosos", "cargas para la sociedad y sus familias", con frases como "que se queden en sus casas" dirigidas a personas con discapacidad. Estos estereotipos frecuentemente se propagan a través de los medios masivos postsoviéticos ${ }^{(1,22,23)}$. Es por esto que este artículo se centra en la representación de la discapacidad así como en las autorepresentaciones de personas discapacidades a través de sus historias orales.

\section{FUENTES Y MÉTODOS}

Este artículo es el resultado de la primera etapa de una investigación sobre la representación de la discapacidad y de las personas discapacitadas entre personas sin discapacidad, además de la autorepresentación de este fenómeno en las personas que tienen discapacidad en la Rusia contemporánea. Esta primera etapa se llevó a cabo entre febrero de 2014 y diciembre de 2016 en Moscú, Nizhny Nóvgorod y Ekaterimburgo (grandes centros urbanos ubicados en las regiones de Volga y Ural). Las fuentes principales de esta investigación fueron de campo: los resultados de observación participante (principalmente en centros y organizaciones para personas con discapacidad en Moscú, la región de Moscú y Nizhny Nóvgorod), las transcripciones de varias entrevistas realizadas a expertos (líderes y activistas de estas organizaciones) y 27 entrevistas en profundidad a personas discapacitadas. Las entrevistas (que fueron grabadas y transcriptas) se realizaron tanto personalmente, como a través de Skype y correo electrónico. Los informantes fueron localizados en los centros de discapacidad a través de la técnica "bola de nieve", en la cual amigos y colegas recomendaban a otras personas conocidas. Una fuente adicional pero muy importante fue Internet: las redes sociales (principalmente Live Journal) y páginas web en las que personas con discapacidad escriben sus historias de vida o relatan episodios de sus vidas que tienen que ver con la experiencia de discapacidad. Se eligieron personas con diferentes deficiencias y diferentes momentos de ocurrencia de la discapacidad -innata, repentina (después de los 18 años de edad) o de a poco (como resultado de una enfermedad o de las consecuencias distales de un trauma)- entendiendo que todos los casos con sus particularidades presentan la posibilidad de que la personas con discapacidad se sientan Otros.

En esta etapa se implementó un abordaje cualitativo mediante el método de historia oral, fructífero para el estudio de identidades 
culturales, problemas de comportamiento, representación y la diseminación de nociones y etiquetas. El método de historia oral es un tipo de entrevista en profundidad en la cual el informante cuenta su historia, abarcando aspectos concretos de los problemas de su propia experiencia. En este estudio, dichos aspectos se relacionaron con la percepción de la discapacidad en general y la propia discapacidad, incluyendo las actitudes de personas "capacitadas" (24,25,26).

Entre los informantes, se encuentran personas con discapacidades sensoriales (ceguera, baja visión, baja audición) y físicas (trastornos de la columna, enfermedades del sistema músculo-esquelético humano). Doce personas tenían discapacidades innatas o desde la infancia, mientras quince experimentaron discapacidad repentina después de los 18 años de edad (como resultado de una enfermedad, accidente o similar). Los 11 hombres y 16 mujeres informantes tenían entre 19 y 66 años de edad y todos trabajaban, estaban buscando empleo al momento de la entrevista, o eran estudiantes. Adicionalmente, se realizaron seis entrevistas con expertos en Moscú y Nizhny Nóvgorod. Algunos fragmentos de las historias de vida analizadas se tomaron de Internet ${ }^{(27,28,29)}$. Se informó a todos los participantes que, bajo la política de confidencialidad de la investigación, sus entrevistas se utilizarían anónimamente (todos los nombres fueron cambiados) y que podían parar la entrevista o negarse a responder a cualquier pregunta. No hay muestreos representativos en la investigación cualitativa por lo que no estaba indicada ninguna distribución especial entre las regiones, las edades o los sexos; sin embargo, se utilizó el principio de "saturación teórica", según el cual el investigador recoge los datos suficientes para su investigación hasta el punto de que un nuevo material no aporta información adicional para el objeto de estudio ${ }^{(24,26)}$.

\section{RESULTADOS}

\section{Otros para siempre}

Muchas personas discapacitadas comparten estereotipos negativos respecto de lidiar con la discapacidad. Frecuentemente, intentan distanciarse de la discapacidad y de las personas con deficiencias. Por ejemplo, Larrisa G., que tenía 54 años, baja visión y deficiencia visual innata, era ex empleada de un negocio y estaba sin trabajo al momento de la entrevista, relató:

Nunca pensé que era defectuosa. Ves, en mi familia nadie decía que era una persona discapacitada, una persona defectuosa. Mi madre me crió de tal manera que nunca sería defectuosa. (Larissa G., Moscú, 2015)

Esta opinión es común entre personas discapacitadas en Rusia. Difiere del enfoque predominante en los países occidentales, en el cual las personas con discapacidad tienen derechos y posibilidades iguales, que la sociedad debería usar para su mejor desarrollo.

En la investigación sobre discapacidad es necesario no solo diferenciar entre las deficiencias o defectos (sensoriales, físicas o mentales) sino también entre los grupos de personas discapacitadas. Como se mencionó con anterioridad, la discapacidad en la URSS y en la Rusia postsoviética estaba y está estrechamente conectada con la posibilidad de trabajar. Sin embargo, es muy importante diferenciar entre personas con discapacidad innata o personas que adquirieron la discapacidad en su infancia y personas que experimentaron una discapacidad repentina después de los 18 años. Estas categorías de personas discapacitadas implican diferentes experiencias personales, sociales y culturales, además de diversas nociones sobre la discapacidad, en general, y su deficiencia, en particular. A partir de las fuentes del estudio, se pueden definir varios aspectos de la experiencia personal percibidos por personas con discapacidad. 
En todos los grupos y categorías se observa el sentimiento de alteridad, es decir, que las personas se consideran muy diferentes a otras personas supuestamente "normales". Al momento de la entrevista, Natalia B. tenía 28 años y discapacidad innata (síndrome de Ménière, una enfermedad del sistema músculo-esquelético humano), y eligió no buscar el reconocimiento del Estado por su discapacidad, no estaba casada, tenía estudios secundarios, vivía con su madre en Ekaterimburgo, y era música. Su apodo en las redes sociales era Djimbo Di, el nombre que se utiliza en el resto de este trabajo. Según ella escribe en su diario en línea, "siempre entendí que era un cuervo blanco y un cordero azul. Siempre, en mi infancia, en la escuela, en todos lados"(27). Esta expresión particular, "cuervo blanco y cordero azul", afín a la noción de oveja negra, demuestra la fuerza de su sentimiento de otredad.

\section{Cuidados y opresión}

Las personas con discapacidades innatas o desde la infancia frecuentemente cuentan los "hipercuidados" que recibieron de sus parientes, especialmente padres que no creían que sus niños/as discapacitados/as pudieran ni siquiera realizar tareas sencillas en el hogar ("se va a lastimar con el cuchillo", "va a romper el vaso").

Olga S. tenía 48 años, empezó a tener deficiencias visuales en su infancia, estaba incluida en el grupo 1 de discapacidad, estaba casada, no tenía hijos, trabajaba como masajista y vivía en Moscú. Ella recordó:

Cuando era niña, de edad escolar, si siquiera muy pequeña, mi madre me decía "No toques el horno" o "No agarres el cuchillo, haré todo yo misma". Cuando me casé no podía cocinar, limpiar el departamento, nada. Y cuando empecé a hacer todo eso mis parientes estaban sorprendidos: "Eres ciega, cómo puedes hacer estas cosas?" (Olga S., Moscú, 2014)
Djimbo Di también escribió en su Live Journal: "en mi infancia yo sufría constante y permanentemente de hipercuidado"(27).

Olga G., que tenía 42 años y baja audición. Tenía discapacidad desde los 9 años. Estaba incluida en el grupo 3 de discapacidad, no estaba casada y vivía sola en Moscú, donde trabajaba como diseñadora web, relató:

Mi padre no estaba muy nervioso con respecto a mí pero mi madre y mi abuela se volvían locas, pensando qué iba a hacer cuando estuviera sola. Repetían: "No podés llamar a un electricista, no podés hacer esto, no podés hacer lo otro". (Olga G., Moscú, 2014)

Este problema se ve reflejado en la mayoría de las narrativas orales de personas con discapacidad innata. Muchos líderes o activistas de organizaciones para personas con discapacidad enfatizaban que muchos niños/ as con discapacidad (especialmente con deficiencias severas como ceguera, sordoceguera, trastornos de la columna y similar) no pueden realizar tareas elementales del hogar y a veces ni pueden realizar su propio aseo personal.

A veces, los niños/as con deficiencias relativamente "ligeras" como, por ejemplo, la baja visión de Larissa G., son criados como niños/as "normales" y la palabra "discapacidad" ni siquiera se menciona en la familia para poder escapar de este estigma.

Olga B. tenía 56 años, baja visión y estaba incluida en el grupo 2 de discapacidad. Estaba casada y tenía dos hijos, vivía en Moscú y era maestra de inglés. Según explicó:

\footnotetext{
No, mis padres nunca hicieron hincapié en mi deficiencia; me criaron como una persona normal. Siempre me decían: "Tienes que hacer todo, vas a hacer todo, no te portes como una niña lastimosa, eres normal". (Olga B., Moscú, 2015)
}

Este mismo tratamiento, a veces puede encontrarse en familias con niños/as que 
tienen deficiencias severas. Por ejemplo, Elena N. tenía 37 años, nació con baja visión y luego perdió la visión por completo, estaba dentro del grupo 1 de discapacidad, estaba casada, tenía dos hijos, vivía en Moscú y, al momento de la entrevista, no trabajaba. Contó que había terminado la secundaria en el pueblo de Aleksándrov (región de Vladimir), luego asistió a la Facultad de Derecho en la misma ciudad, y finalmente se recibió en el Departamento de Derecho de la Universidad Estatal de Moscú. Hablando de las actitudes de su familia hacia ella, dijo: "Mi mamá siempre decía, ¿¿Qué vas a hacer cuando yo me muera? Tienes que hacer todo tú misma" (Elena N., Moscú, 2014).

\section{Aislamiento y soledad}

Estas actitudes y percepciones de un/a niño/a discapacitado/a como una criatura débil, indefensa y digna de lástima resulta frecuentemente en su aislamiento del resto de sus pares y, a su vez, en una sensación de soledad que puede durar años. Estos/as niños/as suelen pensar que nadie los necesita y hasta se sienten marginados.

Vladimir V., que tenía 42 años y discapacidad innata (trastorno del sistema músculo-esquelético), no trabajaba y vivía con su madre en Nizhny Nóvgorod, recordó:

Mi madre me dijo que cuando yo era niño no se animaba a dejarme jugar con los niños normales. Entonces no fui al jardín. No tenía amigos, siempre iba de la mano de mi mamá. Y toda mi vida me sentí un paria. (Vladimir V., Nizhny Nóvgorod, 2015)

Djimbo Di escribió:

En mi infancia, después de la muerte de mi abuela que mantenía la casa, de repente me quedé muy sola. Mi madre quería escaparse de mi crianza y estaba absolutamente consumida en su trabajo. Con frecuencia viajaba por trabajo y me dejaba con mi bisabuela que tenía 87 y baja audición, pero que estaba llena de energía. Vivía con ella dos o hasta tres semanas al mes y me sentía muy sola. ${ }^{(27)}$

\section{Descendiendo al inframundo}

Las personas con discapacidades repentinas, con frecuencia se consideran Otros y además "inútiles," "defectuosos," "miserables". Este sentimiento es especialmente profundo luego del trauma o la enfermedad que resultó en la discapacidad, dado que el nivel de rehabilitación social y psicológica para personas con discapacidad en Rusia es muy bajo. Algunas personas eligen Ilevar la etiqueta toda su viva, mientras otras eligen estrategias activas para superar el estigma.

Al momento de la entrevista, Maksim V. tenía 37 años, adquirió la discapacidad a los 32 años como resultado de un accidente automovilístico y estaba en el grupo 1 de discapacidad por su parálisis vertebral. Antes del accidente era un hombre de negocios, estaba casado y tenía una hija, no trabajaba y vivía solo en Nizhny Nóvgorod. Recordó:

\section{Al principio era muy difícil, era terri- ble. No sabía vivir, si valía la pena vivir. Pero mis amigos venían en ese momento a apoyarme, mi esposa no me había dejado todavía. Ahora estoy muy solo, me siento en una jaula de hierro de la cual no me puedo liberar. No tengo nada, salvo Internet, gracias a Dios. Me ayuda, aunque no sé a quién enviar mensajes. [...] Nadie se interesa por mis problemas. A veces escribo car- tas y las envío a correos electrónicos que yo invento. Quizás alguien me conteste. (Maksim V., Nizhny Nóvgorod, 2015)}

Vladimir K. tenía deficiencia auditiva y estaba en el grupo 3 de discapacidad después de haber perdido su audición a los 44 años como resultado de la influenza. Era profesor de química en una de las universidades de Moscú. Al momento de la entrevista, Vladimir estaba casado y tenía un hijo, no trabajaba y vivía mayormente en la cabaña 
familiar en la región de Moscú. Fue entrevistado vía correo electrónico:

Al principio me parecía que me iba a volver loco. Todo -el trabajo, la familia, los amigos- estaba seguro que todo eso había terminado. Nadie necesita a una persona discapacitada. No puedo escuchar nada, ni un audífono ayuda. Todo el mundo tiene que escribir lo que me quiere decir. De a poco me fui acostumbrando a la situación, pero ya no podía ser docente. Ahora paso mucho tiempo solo en nuestra cabaña, tenemos un manzanar ahí y me gusta. [...] Esto también es vida aunque es una vida muy solitaria, vivo alejado de todo. (Vladimir K., Moscú, 2014)

\section{Compañeros de la escuela y los docentes}

El sentimiento de alteridad, que los diferencia de todos los demás, de las personas "capacitadas", con frecuencia se profundiza durante los años escolares, especialmente, cuando niños/as con discapacidad asisten a escuelas inclusivas. Este sentimiento aparece a menudo en las narrativas orales. Las personas con discapacidad suelen enfatizar que este sentimiento fue influenciado por las actitudes de sus compañeros y, especialmente, de los docentes. Se han descrito estas interacciones complejas en la escuela en referencia a niños/as con varios trastornos, tanto físicos como mentales ${ }^{(30,31)}$. Las actitudes negativas, como acoso o indiferencia hacia niños/as con discapacidad, sugiere la necesidad de reconsiderar el rechazo de escuelas especiales en la Rusia contemporánea en favor de una educación inclusiva.

Por ejemplo, Elena N. asistió a una escuela inclusiva y luego a una facultad, pero sufrió las actitudes de los profesores:

Los docentes me percibieron de otra manera. Algunos me ayudaron. Otros hasta intentaban cuidarme a su manera: "siéntate y no hagas nada, esto es dema- siado difícil para ti". Algunos me vieron como una carga para ellos porque me tenían que ayudar o prestarme especial atención. [...] Algunos hasta me dijeron: "Dios te castigó por algo". (Elena N., Moscú, 2014)

Djimbo Di también recordó sus años escolares:

En mi escuela siempre era un cuervo blanco y un cordero azul. Nunca hablaba con nadie si no había motivo. Simplemente confiaba en mí misma y no buscaba ser "como todos los demás". Los maestros querían que me fuera de la escuela y que estudiara en mi casa. Les parecía que no valía la pena invertir su tiempo en mí ya que no iba a estudiar ni trabajar en ningún lado. ${ }^{(27)}$

Algunos informantes, con discapacidad tanto innata como repentina, se sienten sujetos a un tipo de "injuria injusta" que la vida, Dios, la sociedad, o el destino les causó. A veces este sentimiento resulta en un odio hacia sí mismos.

Olga G. contó de su "vida injusta" durante la entrevista, a pesar de su buen trabajo, departamento y salario:

Yo sé que soy defectuosa, fea [Olga es una mujer atractiva] y yo tengo amigos que son como yo, sordos. No puedes imaginar su nivel intelectual, son idiotas. [...] A veces intento mostrarles que no soy tan idiota y fea como ellos. Quiero ser como todos los demás, pero la verdad es que soy igual de idiota y fea que ellos.

Tamara Cheremnova, de 58 años de edad, escribía literatura infantil, y tenía discapacidad innata (parálisis cerebral). A los seis años, sus padres la llevaron a un orfanato especial donde los médicos definieron su enfermedad como "retardo mental severo". A pesar de esto, Tamara aprendió sola a leer y escribir; luego -también sola- rindió el programa escolar obligatorio y empezó a escribir libros infantiles. El diagnóstico de 
"retardo mental" fue rescindido. Ahora sus libros están traducidos a numerosos idiomas. Ella vive en el instituto especial para personas con discapacidad $N^{\circ} 2$ en la ciudad de Novokuznetsk ${ }^{(28)}$. Escribe:

Al principio no quería contactarme con nadie. A la noche mordía la almohada, me odiaba a mí misma, a mi parálisis cerebral. Por este terrible enfermedad mis brazos y piernas no funcionaban bien y además había recibido ese diagnóstico injusto y ofensivo: ¡me acusaban de ser mentalmente defectuosa! ${ }^{(28)}$ [énfasis añadido]

\section{Después de la escuela}

Después de terminar la escuela muchos informantes siguieron su educación en terciarios o universidades. En este periodo la autopercepción y la autorepresentación de personas con discapacidades innatas suele cambiarse. Si se comparan las actitudes hacia estas personas entre escuelas y universidades podemos ver que los estudiantes con discapacidad normalmente interactúan bien con sus profesores pero, al mismo tiempo, no tienen contacto con estudiantes "normales". Como resultado siguen sintiéndose Otros.

Vladimir Z., tenía 54 años y deficiencia visual, estaba en el grupo 2 por una discapacidad que adquirió a los 14 años después de una enfermedad. Primero asistió a una escuela inclusiva, luego a una escuela especial. Al momento de la entrevista era profesor de historia en una escuela especial de Moscú, estaba casado y tenía dos hijos. Recordó:

En la universidad me sentía más cómodo que incluso en la escuela. No tuve problemas con profesores, ellos entendían mi discapacidad. Una o dos veces a alguien le costó entender que yo no podía leer el pizarrón o algo así. Pero simplemente explicaba y entendían. [...] Respecto a los estudiantes, la situación era peor. Nadie dijo ni hizo nada malo, no. Pero eran indiferentes, no me prestaban atención y me sentía, bueno, muy excluido. (Vladi-

mir Z., Moscú, 2014)

Más allá de las discapacidades y las dificultades resultantes, muchos de los informantes se graduaron de buenas universidades o lograron buenas carreras profesionales. Sin embargo, muchos de ellos, especialmente quienes habían asistido a instituciones especiales, tenían sentimientos de "anormalidad" que relacionaron con la discapacidad. Por lo tanto, siguieron sintiéndose (y siguieron siendo) estigmatizados.

Por ejemplo, Bayramkis A., que tenía 54 años, deficiencia visual innata y estaba dentro del grupo 2 de discapacidad, había ido a una escuela especial para niños/as con deficiencia visual en Daguestán, luego a un terciario médico para personas con discapacidad visual en Kislovodsk. Al momento de la entrevista, era masajista y vivía en Moscú, tanto su marido como su hijo habían fallecido. Bayramkis contó:

Cuando era joven y había empezado a trabajar me sentía constantemente defectuosa, me daba vergüenza mi baja visión. Creo que me sentí así porque vivíamos en un terciario especial en Kislovodsk y todo el mundo ahí tenía discapacidad visual. Ahora los estudiantes del terciario vuelven a sus casas los fines de semana, pero nosotros vivíamos ahí hasta en las vacaciones, a veces aún en las vacaciones de verano. No teníamos nada de comunicación con otras personas, vivíamos en el mundo separado. Después me quedé dos años más en el terciario de Kislovodsk. Entonces durante 12 años viví en un mundo en el que todos tenían discapacidad visual. Cuando me fui de ese mundo y empecé a trabajar, siempre me sentía discapacitada, me sentía mal, avergonzada. Siempre entendía que era discapacitada, defectuosa. (Bayramkis A., Moscú, 2014)

Esta actitud hacia la discapacidad también es común entre informantes con discapacidades repentinas como el conocido 
escritor y activista Aleksey Grafov, quien se volvió ciego durante su carrera universitaria. En sus trabajo describe que de repente comprendió que su discapacidad era para siempre y que ahora era una persona discapacitada ${ }^{(29)}$.

\section{El trabajo y actitudes hacia la discapacidad}

Casi todos los informantes advirtieron que cuando intentaban buscar un empleo sufrían de diferentes formas de discriminación. A veces, los informantes hasta intentaban mantener sus defectos en secreto, no llevaban sus lentes o audífonos, no tenían los anteojos puestos en la entrevista, etc. Explicaron que era muy importante portarse "como personas normales" durante la entrevista y en las primeras semanas en su trabajo para que sus empleadores entendieran que podían hacer todo "como una persona normal" y se acostumbraran a sus deficiencias. Este comportamiento refleja el abordaje de la discapacidad que Garland Thompson define como lo "normato", o la perspectiva de personas "capacitadas" respecto de todo lo relacionado con la discapacidad y las personas discapacitadas; esta perspectiva "normata" es típica de personas supuestamente "normales" que aplican sus nociones, su formas de ver y su política a personas con discapacidad ${ }^{(32)}$.

Muchos informantes además enfatizaron que durante sus carreras profesionales fueron discriminados por sus discapacidades (sus empleados y colegas no creían que personas discapacitadas podían trabajar como "gente normal"). Vera Z., al momento de la entrevista tenía 62 años, deficiencias visuales y auditivas y estaba dentro del grupo 2 de discapacidad. Estaba casada y tenía un hijo. También era psicóloga y trabajaba en un centro de investigación en Moscú como Jefa de Departamento. Ella mencionó:

Siempre supe que el director de mi centro y de otros creen que no puedo trabajar como una persona normal. Por supuesto, no me lo dicen. Pero nunca me ascendieron como miembro del
Consejo Académico, aunque tengo muchas publicaciones. Mi carrera -si se puede hablar de la mía como una carrera en investigación- no fue muy exitosa. Sí, me ascendieron a Jefa de Departamento. Pero para ese entonces ya tenía 60 años, no tenía energía para trabajar como jefa. Cuando tenía 50, tenía energía, ideas. Quería organizar el trabajo de este Departamento. Ahora solo estoy cansada, no tengo más energía. Pero no me ofrecieron el puesto antes. (Vera Z., Moscú, 2014)

Olga S., que tenía 58 años, deficiencia visual de su infancia y estaba dentro del grupo 1 de discapacidad, trabajaba como masajista, estaba casada y no tenía hijos, y vivía en Moscú, también dijo:

Cuando era joven me ofrecieron formar para de un terciario médico para enseñar distintos métodos de masaje, distintos tipos. Había terminado el terciario en Kislovodsk, es muy bueno. Pero algo pasó y no me invitaron. Alguien me dijo que simplemente no querían contratar a una persona ciega. Hace un año un amigo me preguntó si quería enseñar. Le conteste: "No, ahora estoy cansada, ya no tengo la energía, ahora no quiero ese trabajo." Cuando era más joven quería trabajar y lo podía hacer muy bien pero nadie creía que podía ser docente. (Olga S., Moscú, 2015)

Algunos informantes recordaron que sus empleados o colegas Ilegaron a insultarlos cuando querían avanzar en sus carreras profesionales. Larissa G. quería un mejor trabajo, y recordó que su colega le dijo: "Estás ciega, ¿cómo vas a hacer el trabajo? No puedes, tienes que seguir trabajando acá" (Larissa G., Moscú, 2015).

Las personas discapacitadas no sienten estas actitudes prejuiciosas en las organizaciones especiales para personas con discapacidad que sobreviven desde la época soviética. Sin embargo, es muy difícil tener éxito en estas organizaciones: lo sueldos son bajos, 
es difícil ascender y, además, el número de puestos disponibles está decreciendo.

\section{Miedo e indiferencia}

El motivo general de las narrativas orales de las personas discapacitadas tiene que ver con la indiferencia del mundo, o más específicamente, de la gente con respecto a los problemas de las personas discapacitadas. Por ejemplo, Anton P., que al momento de la entrevista tenía 33 años, deficiencia visual innata y estaba dentro del grupo 1 de discapacidad. Se recibió de la Universidad Estatal de Moscú y ahora trabaja como director de una empresa comercial. Vivía en Moscú y no estaba casado. Hizo un comentario sobre las personas ciegas en Rusia, pero podría extenderse a las personas discapacitadas en general: "Sabemos que en este país todo el mundo siente lástima por una persona ciega. $A$ veces también se la puede admirar" (Anton P., Moscú, 2015).

Anton hace referencia a los programas en los medios masivos sobre los "logros" de las personas discapacitadas, como atletas paralímpicos, cantantes y similares. Al mismo tiempo, la opinión pública no se interesa por las vidas cotidianas de personas con discapacidad, la gente no sabe nada de ellas y los medios apenas tocan el tema. Entonces la "lástima" es esporádica y puede ser dañina.

Vadim E., que tenía 28 años, deficiencia visual innata y estaba dentro del grupo 1 de discapacidad, se recibió de la Universidad de Psicología de Moscú, no trabajaba y no estaba casado, contó:

Una vez estaba esperando a un amigo en la calle. Estaba cerca de una boca de subte y sostenía una lata con agua mineral en la mano. De repente, alguien tiró una moneda en la lata. Puedes imaginar, ipensó que estaba pidiendo! ¿No se dio cuenta que llevaba buena ropa, que estaba limpio, que solo estaba parado esperando? Arruinó mi agua, por supuesto. (Vadim E., Moscú, 2014)
Estas actitudes hacia personas con discapacidad como pobres, que mendigan o piden limosnas, indefensas, etc., es típico en muchas sociedades y culturas. Por ejemplo, la imagen de una persona ciega como mendigo/a es ampliamente difundido en la cultura inglesa ${ }^{(11)}$.

En algunos casos, los informantes hablaron de prejuicios y miedos que sienten las personas "normales" al entrar en contacto con personas con discapacidad. Estos no son miedos del comportamiento no socialmente aceptable asociado con personas con trastornos mentales ${ }^{(12)}$ o nociones de la contagiosidad de la deficiencia, como se mencionó anteriormente con respecto a la ceguera ${ }^{(11)}$. Los informantes enfatizan que las personas frecuentemente tienen miedo de perder tiempo en ayudar a una persona con discapacidad y que temen que la persona discapacitada vaya a romper algo, caerse o algo similar, y que llevaría tiempo y energía tener que ayudarla. Elena N. mencionó:

\begin{abstract}
Siempre me pareció que nos temen. No nos conocen y tienen miedo. Piensan: "por ahí voy a tener que gastar tiempo o algo así en esta persona discapacitada". Me da la impresión de que tienen miedo de lo que les podría pedir. Quizás sería una carga y entonces intentan evitarme, siempre lo sentí así. (Elena N., Moscú, 2014)
\end{abstract}

Frecuentemente, las personas que quieren ayudar no saben qué hacer y les da vergüenza. Valentina $M$. tenía 51 años, discapacidad repentina (esquelética) y estaba en el grupo 2 de discapacidad. Era maestra y, al momento de la entrevista, trabajaba en la casa, estaba casada, tenía un hijo y vivía en Moscú. Ella relató el siguiente incidente:

Una vez estaba yendo a algún lado en tranvía. Yo camino con dos bastones especiales y es muy difícil subir las escaleras del tranvía. Pero más difícil aún es bajar. El tranvía paró e intenté salir. Era muy difícil, incómodo y hasta doloroso para mí. Nadie me ofreció ayuda. 
Finalmente, una chica joven se acercó y me ayudó. Después me dijo que ella tenía miedo de lastimarme, y que no sabía qué hacer. (Valentina M., Moscú, 2016)

Como resultado de estos miedos, se observa una evasión pública y personal de las personas discapacitadas.

\section{CONCLUSIONES}

Estos miedos, la evasión y los comportamientos prejuiciosos hacia las personas discapacitadas tienen sus raíces en los tiempos antiguos. Son miedos de los Otros, desconocidos y posiblemente peligrosos. Sin embargo, estos miedos y actitudes evasivas son típicas también de las culturas modernas ${ }^{(15)}$; por ejemplo, Bolt analizó apuntes sobre la contagiosidad de la ceguera que existieron en el siglo $X X^{(11)}$. Estas actitudes prejuiciosas son el resultado de la estigmatización de la discapacidad y de las personas discapacitadas, tal como se desarrolló en el texto arriba. Además, son la consecuencia de un punto de vista "normato" en el que las personas con discapacidad siguen siendo Otros ${ }^{(32)}$ pero sus problemas los resuelven las personas "capacitadas", "normales". En los contextos soviético tardío y postsoviético, estas actitudes se generaron a partir del concepto del cuidado social de personas discapacitadas que frecuentemente estaban muy enfermas e indefensas, como las personas con discapacidad mental ${ }^{(23)}$. Los académicos enfatizan que estas actitudes resultaron no solo en actitudes negativas hacia personas discapacitadas sino una subestimación del rol de las personas con discapacidad en la sociedad y hasta la negación de su existencia, formulada en la frase célebre "no hay inválidos (personas discapacitadas) en la URSS"(3). En el periodo postsoviético, personas con diferentes deficiencias todavía son percibidas como "inútiles", "una carga para la sociedad", y en este estudio se mostró que las personas discapacitadas a veces comparten estos estereotipos. Estas nociones están parcialmente arraigadas en el contexto histórico: las actitudes hacia las personas discapacitadas en la cultura rusa del pasado $^{(23)}$ las hacían ver como miserables, el resultado de los pecados de sus padres. En la época stalinista de la URSS, las personas discapacitadas se consideraban "inútiles" porque no podían trabajar como personas "normales"(33,34). Más allá de todos los cambios y transformaciones que tuvieron lugar en la Rusia del siglo XX, algunas de estas nociones aún existen, de tal manera que se puede sentir pena por una persona discapacitada, pero no tener ningún deseo de tener contacto o ni siquiera verla, salvo en los casos especiales de sus "logros increíbles".

Los medios masivos promueven estas actitudes; un responsable de una organización en Nizhny Nóvgorod afirmó que no podía acordarse de ningún programa televisivo o radial en muchos años que tuviera que ver con los problemas reales de las personas discapacitadas. Las organizaciones para personas con discapacidad que sobreviven desde la época soviética no cuentan con los fondos suficientes para mejorar la situación. De a poco, estas organizaciones se van convirtiendo en clubes para las personas discapacitadas y tienen muy pocos recursos. No pueden y no intentan luchar por los derechos de las personas discapacitadas con respecto a la discriminación que enfrentan en campos diversos, como la educación, y el empleo, una situación típica en algunos estados postsoviéticos $^{(35)}$. Tampoco pueden mejorar las actitudes ambivalentes o hasta negativas acerca de las personas discapacitadas en la sociedad rusa como, por ejemplo, sentimientos de miedo e indiferencia. En muchos casos estas organizaciones simplemente promueven la "admiración de logros", llevando adelante concursos y muestras de dichos "logros". Como resultado, la evasión es una reacción típica a las personas discapacitadas en la Rusia postsoviética. Como pudimos constatar, estas actitudes afectan la autopercepción y la autorepresentación de las personas discapacitadas e impiden su integración. 


\section{AGRADECIMIENTOS}

Esta publicación fue realizada con al apoyo financiero de la Fundación Rusa para las Humanidades $\left(N^{\circ} 15-06-05883 / 17\right)$.

\section{REFERENCIAS BIBLIOGRÁFICAS}

1. Allport GW. The nature of prejudice. London: Addison-Wesley; 1954.

2. Goffman E. Stigma and Social Identity. In: Stigma: Notes on the Management of Spoiled Identity. New Jersey: Prentice-Hall; 1963.

3. Phillips S. "There are no invalids in the USSR!" A missing Soviet chapter in the new disability history. Disability Studies Quarterly. 2009;29(3):936.

4. Naberushkina EK. Invalidy v bolshom gorode: problemi sitsialnogo grazhdanstva [Disabled people in the large city: problems of social citizenship]. Moscow: Variant, TsPGI; 2012.

5. Rasell M, larskaia-Smirnova E, (ed.). Disability in Eastern Europe and the former Soviet Union: History, policy and everyday life. New York: Routledge; 2014.

6. World Health Organization. Disabilities [Internet]. 2016 [citado 2016 ene 26]. Disponible en: https://tinyurl.com/n5hycar.

7. World Health Organization. New world report shows more than 1 billion people with disabilities face substantial barriers in their daily lives [Internet]. 2011 [citado 2016 ene 26]. Disponible en: https://tinyurl.com/lqs3bsa.

8. Russian Federation, Federal State Statistics Service. The situation of disabled people [Internet]. [citado 2016 ene 26]. Disponible en: https://tinyurl.com/n772hrc.

9. United Nations, Human Rights Office of the High Commissioner. Convention on the Rights of Persons with Disabilities [Internet]. 2006 [citado 2016 ene 26]. Disponible en: https://tinyurl.com/bs7w8y3.

10. World Health Organization. World report on disability [Internet]. 2011 [citado 2016 ene 28]. Disponible en: https://tinyurl.com/mxt58la.

11. Bolt $\mathrm{D}$. The metanarrative of blindness: A rereading of Twentieth-Century Anglophone writing. Ann Arbor: University of Michigan Press; 2014.

12. Luse A, Kamerade D. Between disabling disorders and mundane nervousness: represen- tations of psychiatric patients and their distress in Soviet and post-Soviet Latvia. In: Rasell M, larskaia-Smirnova E, (eds.). Disability in Eastern Europe and the former Soviet Union: History, policy and everyday life. New York: Routledge; 2014.

13. Linton S. Claiming disability: knowledge and identity. New York: NY University Press; 1998.

14. Gerber DF, (ed.). Disabled veterans in history. Ann Arbor: University of Michigan Press; 2000.

15. Corker M, Shakespeare T. Disability / postmodernity: Embodying disability theory. New York: Continuum; 2002

16. Johnston D. An introduction to disability studies. 2nd ed. Oxford: David Fulton Publishers; 2005.

17. Bolt D. From blindness to visual impairment: Terminological typology and the social model of disability. Disability and Society. 2005;20(5):539-552.

18. Siebers T. Disability theory, boldly rethinking of the last thirty years from the vantage point of disability studies. Ann Arbour: University of Michigan Press; 2008.

19. Nosenko-Stein E. Nekotorye problemi izuchenia invalidnosti I sotsiokulturnaia antropologia [Some problems of studying disability in social and cultural anthropology]. In: Materialy mezhdunarodnoi nauchno-prakticheskoi konferentsii 'Sovremennaia antropologia: novye dannye, perspektivy razvitia I metodologicheskie printsipy [Proceedings of International Conference 'Modern anthropology: new sources, methodological princeples and perspectives]. Minsk: Institute of History of the National Academy of Sciences of Belarus; 2015.

20. Romanov P, larskaia-Smirnova Ye. Politika invalidnosti: sotsialnoie grazhdanstvo invalidov v sovremennoi Rossii [Disability policy: social citizenship of people with disabilities in contemporary Russia]. Saratov: Nauchnaia kniga; 2006.

21. Watson N, Roulstone A, Carol T, (eds.). Routledge Handbook of Disability Studies. London: Routledge; 2012.

22. Blank HR. Psychoanalysis and blindness. Psychoanalysis Quarterly. 1957;26(1):1-24.

23. Muravieva MG. Kaleki, invalidy ili liudi s ogranichennymi vozmozhnostiami; obzor istorii invalidnosti [Crippled people, invalids or people with disabilities: historical review of disability]. Zhurnal Issledovanii Sotsialnoi Politiki / The Journal of Social Policy Studies. 2011;10(2);151-166. 
24. Bertaux D. Biography and society: The Life History Approach in the Social Sciences. Beverly Hills: University of California Press; 1981.

25. Grele RL. Envelopes of sound: The art of oral history. New York: Praeger; 1991.

26. Hummersley M. The dilemma of qualitative method: Herbert Blumer and the Chicago Tradition. New York: Routledge; 1989.

27. Dorogu ukazyvaet mechta [A dream shows the right path] [Internet]. 2013 [citado 2016 ene 26]. Disponible en: https://tinyurl.com/mffbxxw.

28. Zdravsvuyte, dobrye ludi [Hello, good people] [Internet]. 2011 [citado 2016 ene 26]. Disponible en: https://tinyurl.com/lgreh5r.

29. Grafov VA. Zapiski slepogo [Essays of a blind man]. Sibirskie ogni [Siberian lights] [Internet]. 2009 [citado 2016 ene 26];(10). Disponible en: http://www.sibogni.ru/content/zapiski-slepogo.

30. Butovskaya ML, Loutsenko YK, Tkacheva KL. Buling kak sotsiokulturny fenomen I efo sviaz s chertami lichonsti u mladshikh shkolnikov [BuIlying as a sociocultural phenomenon and its relation to personality traits among younger school children]. Etnograficheskoie obozrenie / Ethnograghic review. 2012;5:139-150.
31. Vishnevskaya VI, Butovdkaya ML. Fenomen shkolnoy travli: agressory I zhertvy $\mathrm{v}$ rossiyskoy shkole [Phenomenon of scnoll bulling: agressors and victims in Russian school]. Etnograficheskoie obozrenie / Ethnographic review. 2010;2:55-68.

32. Garland-Thomson R. Extraordinary bodies: Figuring physical disability in American culture and literature. New York: Columbia UP; 1997.

33. Fieseler B. Soviet-style welfare: the disabled soldiers of the 'Great Patriotic War.' In: Rasell M, larskaia-Smirnova E, (eds.). Disability in Eastern Europe and the former Soviet Union: History, policy and everyday life. New York: Routledge; 2014.

34. Bernstein F. Prosthetic promise and Potemkin limbs in late-Stalinist Russia. In: Rasell M, larskaiaSmirnova E, (eds.). Disability in Eastern Europe and the Former Soviet Union: History, policy and everyday life. New York: Routledge; 2014.

35. Phillips S. Citizens or 'dead souls'?: an anthropological perspective on disability and citizenship in post-Soviet Ukraine. In: Rasell $M$, larskaiaSmirnova E, (eds.). Disability in Eastern Europe and the former Soviet Union: History, policy and everyday life. New York: Routledge; 2014.

\section{FORMA DE CITAR}

Nosenko-Stein E. "Nos temen porque somos Otro": actitudes hacia las personas con discapacidad en la Rusia moderna. Salud Colectiva. 2017;13(2):157-170. doi: 10.18294/sc.2017.1140.

Recibido: 13 de septiembre de 2016 | Aprobado: 24 de febrero de 2017

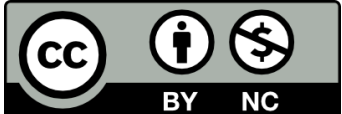

Este obra está bajo una licencia de Creative Commons Reconocimiento-NoComercial 4.0 Internacional. Reconocimiento - Permite copiar, distribuir y comunicar públicamente la obra. A cambio, se debe reconocer y citar al autor original. No Comercial - Esta obra no puede ser utilizada con finalidades comerciales, a menos que se obtenga el permiso.

http://dx.doi.org/10.18294/sc.2017.1140

Este artículo fue traducido del inglés por Vanessa Di Cecco. 